SHORT COMMUNICATION

\title{
Staphylococcus aureus BACTEREMIA IN A BRAZILIAN MIDWEST TEACHING HOSPITAL
}

Ariana Rocha Romão ${ }^{1}$, Marta Antunes de Souza², Vinícius Guilarde Ancelmo ${ }^{3}$, Marilia Dalva Turchi ${ }^{2}$ and Adriana Oliveira Guilarde ${ }^{1,2}$

\section{ABSTRACT}

Staphylococcus aureus bacteremia is a frequent and potentially fatal condition. Resistance to methicillin is considered to be a predictive factor for mortality. The purpose of this study was to evaluate the epidemiological behaviour of $S$. aureus bacteremia in a teaching hospital. The incidence was 5.1 cases per 1,000 admissions. There was a significant improvement in the susceptibility of S. aureus; the incidence of methicillin-resistant S. aureus (MRSA) was $31.3 \%$ (95\% confidence interval (CI) 24.5-39.1); whereas MRSA bacteremia a decade before had accounted for $55.0 \%$ (95\% CI 45.2-64.3) of the cases. Overall mortality due to S. aureus bacteremia was $29.3 \%$. MRSA bacteremia was not a risk factor for death.

KEY WORDS: Bacteremia; Staphylococcus aureus

\section{RESUMO}

Bacteremia por Staphylococcus aureus em um Hospital Escola do Centro Oeste do Brasil

Bacteremia por Staphylococcus aureus compreende uma infecção frequente e potencialmente grave. A resistência à meticilina representa um dos fatores aventados como preditor de letalidade. O objetivo do estudo é avaliar o perfil epidemiológico das bacteremias por $S$. aureus em hospital de ensino. Foi observada incidência de 5,1 casos de bacteremia por 1.000 admissões. A incidência de S. aureus meticilina resistente (MRSA) foi de 31,3\% (intervalo de confiança 95\% (IC) 24,5$39,1)$. Houve uma melhora significativa da suscetibilidade à meticilina em relação ao observado uma década antes, onde a incidência de bacteremia por MRSA era de 55,0\% (IC95\% 45,2-64,3). A letalidade global foi de $29,3 \%$ e bacteremia por MRSA não foi fator de risco para o óbito.

DESCRITORES: Bacteremia; Staphylococcus aureus.

1. Hospital de Doenças Tropicais Dr. Anuar Auad/Secretaria Estadual de Saúde, Goiania, Brazil.

2. Instituto de Patologia Tropical e Saúde Pública, Universidade Federal de Goias (UFG), Goiania, Brazil.

3. Faculdade de Medicina, UFG, Goiania, Brazil.

Corresponding author: Adriana Oliveira Guilarde, Rua 227 quadra 67A, lote 3 e 4, ap. 1503, Setor Leste Universitário 74605-080 Goiania, Goiás, Brasil. E-mail: adrianaguilarde@gmail.com 
Bloodstream infections in critically ill patients are a common fatal condition (Paulsen et al., 2015; Tong et al 2015, Wisplinghoff et al., 2004). Staphylococcus aureus is responsible for approximately $20 \%$ of these infections (Wisplinghoff et al., 2004), and methicillin resistance may occur in more than $50 \%$ of the cases (Gales et al., 2009; Nabera, 2009). The emergence of methicillin-resistant S. aureus (MRSA) strains may influence clinical outcomes, but this issue remains controversial. Some studies have reported that MRSA bacteremia is associated with a significant increase in mortality (Cosgrove et al., 2003; Keynan \& Rubinstein, 2013), but other studies observed no difference in the mortality risk between patients with MRSA and methicillinsusceptible $S$. aureus (MSSA) bacteremia (Cosgrove et al., 2005, Yilmaz et al., 2016). In a previous study performed in a Brazilian teaching hospital, 111 cases of bloodstream infection due to $S$. aureus were recorded from 2000 to 2001, representing the major microorganism found in these infections. MRSA accounted for $55 \%$ of these cases; however, there was no difference in the mortality outcome when comparing MRSA and MSSA (Guilarde et al., 2006). The purpose of this study was to evaluate $S$. aureus bacteremia in this cohort in relation to the reports of the past decade.

This investigation examined a retrospective cohort of patients presenting bacteremia due to $S$. aureus. The investigation was undertaken in a 300-bed teaching hospital (Hospital das Clinicas) associated with a state university (Federal University of Goiás, HC/UFG) in the Brazilian MidWest. The hospital is a tertiary care institution with adult and pediatric units, clinical and surgical patients, and three intensive care units. The institution has a group of professionals working on infection control and prevention, including nurses and physicians. An active surveillance program tracks cases of nosocomial infection, and data are recorded. Cultures were requested routinely when infection was clinically suspected. Whenever bacterial growth was identified by the microbiology laboratory, the clinical data were reviewed by an infectious disease specialist. The antimicrobial susceptibility, source of bacteremia, mortality, and origin of infection were assessed. These data were reviewed from January 2010 through August 2012. The inclusion criteria were as follows: over one year of age, clinical and microbiological evidence of bloodstream infection (BSI) due to S. aureus, and admission to the unit during the study period. Only the first episode of $S$. aureus bacteremia per patient was considered for data analysis. Infections were classified as hospital-acquired when occurring 48 hours after hospital admission and not complications caused by infections present during admission or developed following hospital discharge but related to the previous inpatient care. BSIs were classified as primary when unrelated to any other infection focus or when associated with an intravenous catheter site infection. BSIs were classified as secondary when clinically related to an infection at another site (Garner et al., 
1988). Catheter-related BSI was defined by the isolation of the same organism from cultures of both a catheter segment and peripheral blood with no other apparent source of bacteremia. When no microbiological confirmation was available, defervescence following catheter removal was considered indirect evidence of catheter-related BSI (Pearson, 1996).

Blood cultures were processed using a VITEK 2 automated system, and positive samples were inoculated onto solid media (MacConkey agar, manitol agar and blood agar). Antimicrobial susceptibility was determined according to the recommendations of the Clinical and Laboratory Standards Institute (Clinical and Laboratory Standards Institute, 2011).

The chi-squared test or Fisher's exact test was applied to evaluate differences between proportions, and $95 \%$ confidence intervals $(95 \% \mathrm{CI})$ were calculated. Statistical significance was defined as $\mathrm{p}<0.05$. The SPSS 16.0 (SPSS Inc., Chicago, IL, USA) software program was used for analysis.

The study protocol was approved by the institutional ethics Committee (CEPMHA/HC/UFG).

During the study period, the hospital provided inpatient services to 29,233 patients. A total of 934 blood cultures revealed bacterial growth. Grampositive bacteria numbered $48.6 \%$ of the cultures in $2010,60.8 \%$ in 2011 and $58.1 \%$ in 2012 . There were 5.1 cases of $S$. aureus bacteremia per 1,000 admissions, numbering $24.1 \%$ of the total episodes of bacteremia within the institution. 150 cases of $S$. aureus bacteremia were detected considering only the first sample from each patient. The major sites of infection included primary bacteremia in 114 patients $(76.0 \%)$ and secondary bacteremia in 36 cases $(24.0 \%)$. Among the secondary bacteremia patients, 16 cases $(44.4 \%)$ were associated with respiratory infection, and $7(19.4 \%)$ were associated with surgical site infection.

Oxacillin susceptibility was noted in most of the samples (68.7\%) and $75.0 \%$ were susceptible to Ciprofloxacin. Rifampicin and TrimethoprimSulfamethoxazole (TMP-SMX) were active against $94.3 \%$ and $90.3 \%$ of the samples, respectively. Only $51.7 \%$ of the samples were susceptible to clindamycin. All samples were susceptible to vancomycin, tigecycline and linezolid.

Death was associated with $S$. aureus bacteremia in $29.3 \%$ of the cases $(44 / 150)$ and due to other causes in $4.7 \%$ of the cases. Mortality was more common during nosocomial infection (35.8\% versus $14.8 \%)$ and in patients with a secondary infection ( $42.4 \%$ versus $26.3 \%$ ). More deaths were also observed following MRSA than MSSA infections (38.3\% x 25.2\%), but this difference was not statistically significant $(\mathrm{p}=0.10)$. Other authors have not found MRSA bacteremia connected to a significantly worse outcome compared with MSSA (Tong et al 2015). Several studies have demonstrated that MRSA bacteremia is associated with a significantly higher mortality rate compared 
with MSSA bacteremia, but the higher level of mortality is thought to be due to delays in initial antimicrobial therapy (Wang 2015).

The incidence of $S$. aureus bacteremia has remained stable over the past decade at this institution. During this period, control measures have been persistently applied, even in the context of endemicity. There has been an important reduction in MRSA bacteremia, with a 55.0\% incidence of MRSA over the last decade $(95 \% \mathrm{CI}, 45.2-64.3)$ (Guilarde et al., 2006) and a 31.3\% incidence $(95 \% \mathrm{CI}, 24.5-39.1)$ noted in the present study (Table). Other authors have seen reductions in the incidence of MRSA through the implementation of control measures (Raineri et al., 2007).

Table. Antimicrobial susceptibility of bacteremia by Staphylococcus aureus in a teaching hospital, over two periods

\begin{tabular}{ccc}
\hline Antimicrobial Agent & $\begin{array}{c}2000-2001 \\
(\mathrm{n}=111)\end{array}$ & $\begin{array}{c}2010-2012 \\
(\mathrm{n}=150)\end{array}$ \\
$\begin{array}{c}\text { Guilarde et al. 2006 } \\
\text { Susceptibility (\%) }\end{array}$ & $\begin{array}{c}\text { Susceptibility (\%) } \\
\text { Oxacillin* }\end{array}$ & 68.7 \\
Ciprofloxacin & 45.0 & 75.0 \\
Clindamycin & 52.3 & 51.7 \\
Trimethoprim- & 46.8 & 90.3 \\
Sulfamethoxazole & 77.5 & 100.0 \\
Vancomycin & & \\
\hline
\end{tabular}

$* \mathrm{p}<0.01$

\section{ACKNOWLEDGMENTS}

Fundação de Amparo à Pesquisa do Estado de Goiás (FAPEG) Edital 006/2009, processo 200910267000398

To CNPq (scholarship 313.483/2014-0 to M.D.T)

\section{REFERENCES}

1. Clinical and Laboratory Standards Institute. Performance Standards for Antimicrobial Susceptibility Testing: Twenty-first Informational Supplement M100-S21. Wayne, PA, USA, CLSI; 2011.

2. Cosgrove SE, Qi Y, Kaye KS, Harbarth S, Karchmer AW, Carmeli Y. The impact of methicillin resistance in Staphylococcus aureus bacteremia on patient outcomes: mortality, length of stay, and hospital charges. Infect Control Hosp Epidemiol 26: 166-174, 2005. 
3. Cosgrove SE, Sakoulas G, Perencevich EM, Schwaber MJ, Karchmer AW, Carmeli Y. Comparison of Mortality Associated with Methicillin-Resistant and Methicillin-Susceptible Staphylococcus aureus Bacteremia: A Meta-analysis. Clin Infect Dis 36: 53-59, 2003.

4. Gales AC, Sader HS, Ribeiro J, Zoccoli C, Barth A, Pignatari AC. Antimicrobial Susceptibility of Gram-Positive Bacteria Isolated in Brazilian Hospitals Participating in the SENTRY Program (2005-2008). Braz J Infect Dis 13: 90-98, 2009.

5. Garner JS, Jarvis WR, Emori TG, Horan TC, Hughes JM. CDC definitions for nosocomial infections. Am J Infect Control 16: 128-140, 1988.

6. Guilarde AO, Turchi MD, Martelli CMT, Primo MBG. Staphylococcus aureus bacteraemia: incidence, risk factors and predictors for death in a Brazilian teaching hospital. $J$ Hosp Infect 63: 330-336, 2006

7. Keynan Y, Rubinstein E. Staphylococcus aureus bacteremia, Risk Factors, Complications, and Management. Crit Care Clin 29: 547-562, 2013.

8. Nabera CK. Staphylococcus aureus Bacteremia: Epidemiology, Pathophysiology, and Management Strategies. Clin Infect Dis 48 (Suppl.4): 231-237, 2009.

9. Paulsen J, Mehl A, Askim A, Solligard E, Asvold BO, Damas JK. Epidemiology and outcome of Staphylococcus aureus bloodstream infection and sepsis in a norwegian county 1996-2011: an observational study. BMC Infect Dis 15: 116, 2015.

10. Pearson ML. Guideline for prevention of intravascular device related infections. Part I. Intravascular device-related infections: an overview. Am J Infect Control 24: 262-277, 1996.

11. Raineri E, Crema L, DeSilvestri ALL. Meticillin-resistant Staphylococcus aureus control in an intensive care unit: a 10 year analysis. J Hosp Infect 67: 308-315, 2007.

12. Tong SYC, Davis SJ, Eichenberger E, Holland TL, Fowler VGJ. Staphylococcus aureus infections: epidemiology, pathophysiology, clinical manifestations and management. Clin Microbiol Rev 28: 603-661, 2015.

13. Wang JT, Hsu LY, Lauderdale TL, Fan WC, Wang FD. Comparison of outcomes among adult patients with nosocomial bacteremia caused by Methicillin-Susceptible and MethicillinResistant Staphylococcus aureus: a retrospective cohort study. PLOS ONE 10: 12, 2015.

14. Wisplinghoff H, Bischoff T, Tallent SM, Seifert H, Wenzel RP, Edmond MB. Nosocomial bloodstream infections in US hospitals: analysis of 24,179 cases from a prospective nationwide surveillance study. Clin Infect Dis 39: 309-317, 2004.

15. Yilmaz M, Elaldir N, Balkan II,Arslan F, Batirel AA, Bakici MZ, Gozel MG, Alkan S, Çelik AD, Yetkin MA, Bodur H, Sinirtas M,Akalin H, Altay FA, Sencan I, Azak E, Gundes S, Ceylan B, Ozturk R, Leblebicioglu H, Vahaboglu H, Mert A. Mortality predictors of Staphylococcus aureus bacteremia: a prospective multicenter study. Ann Clin Microbial Antimicrob 15: 7, 2016. 